\title{
Study and Design of Waste Heat Recovery using Organic Rankine Cycle
}

\section{SEYED SAIED HOMAMI ${ }^{1 *}$, AHMAD KHOSHGARD², MARYAM MOMENIFAR ${ }^{3}$, HAMED NEMATI SAYAD ${ }^{4}$ and HAMIDREZA HEIDARIMOGHADAM ${ }^{5}$}

\author{
${ }^{1}$ Islamic Azad University, Islamshahr Branch; Islamic Azad University, South Tehran Branch; Iran. \\ IIslamic Azad University, South Tehran Branch; HSEE Department of MIMT of Iran. \\ ${ }^{3}$ Iran Khodro Industrial Group. \\ ${ }^{4}$ Islamic Azad University, South Tehran Branch. \\ ${ }^{5}$ HSEE Department of MIMT of Iran. \\ Corresponding author E-mail:s_homami@azad.ac.ir
}

http://dx.doi.org/10.13005/ojc/320174

(Received: December 25, 2015; Accepted: February 26, 2016)

\begin{abstract}
ABSTACT
Existing energy crisis in the world has diverted human perspective to the optimum usage of the available energy resources. One of these solutions is waste heat recovery systems[1]. Simultaneous production of fresh water, power and cooling from waste heat improves energy efficiency in industrial applications which could be operated by organic Rankine cycles. In this article, cogeneration of electricity and heat (CHP) in the petrochemical industry, textile and paper production has been reviewed and the usage of aforesaid cycle in these industries is determined. Designing organic Rankine cycle (with operating fluid organic trans-butene) and taking advantage of the excess low pressure steam, a strategy for producing three valuable products of fresh water, power and refrigeration in the petrochemical industries has been offered. Simultaneous production of $10,000 \mathrm{~kg} / \mathrm{hr}$ fresh water, $1533 \mathrm{kw}$ power and access to the lower temperatures of about $226 \mathrm{~K}$ and $260 \mathrm{~K}$ were resulted.
\end{abstract}

Key words: Organic Rankine cycle, CHP, Cogeneration, fresh water, electricity, refrigeration.

\section{INTRODUCTION}

Iran is one of the countries that are located in the semi-arid and arid regions with low annual raining. Generally, these issues have boosted the potential for dehydration and the possibility of drought in Iran. In normal circumstances in some parts of the country, particularly the southern and southeastern regions water supply has made a wide range of problems. Hence, it seems in addition to 
using conventional methods for obtaining the usual fresh water, the need for new guidelines in the country is strongly felt for drinking water by taking into account the efficient use of energy. This is more important when we find that in industrial countries, although with increasing volume and variety of goods and services in production, energy consumption has also been increased. But usage of modern technology and improving the efficiency of production and consumption of energy has caused the rate of increasing energy consumption to cool-down in the process of economic development of countries. One of these technologies, make use of a cycle with the ability to produce simultaneously. Meaning conversion of consecutive or simultaneous production of energy of the fuel into two forms of energy (usually mechanical and thermal) in one unit ${ }^{1}$. The Organic Rankine cycle is an effective way to convert theses heat sources into electrical energy sources. The cycle has the ability to convert low-temperature heat into the energy production. Traditional Rankine cycle, using water as the operating fluid, needs high temperature and a hot source while Organic Rankine cycle (ORC) can produce power at a much lower temperature ${ }^{2}$. The temperature of the hot source can be from 100 to over 250 degrees Celsius. In recent years much researchers have been able to perform it successfully and many ORC systems have been installed in different countries, especially in the United States, Canada, Germany and Italy ${ }^{3}$. Power generation by ORC is from renewable sources and wasting heat with lower levels of energy, such as geothermal energy, biomass, energy of the sun and the waste heat energy from the industry and thermal power stations. In addition, the Organic Rankine cycle can be used to recover energy from exhaust gas of gas power cycle, which improves fuel consumption and the reduction of fuel effect on climate change. ORC and operating fluids were widely studied in different scientific papers and in various applications such as in the recovery of waste heat, geothermal power plant, etc ${ }^{4}$. The first implementation of the Organic Rankine cycle was in the year1881 when a naphtha engine was invented by Frank W Ofledt. In naphtha engine, instead of water, naphtha was used as the operating fluid in order to replace the steam engines of the boats ${ }^{5}$. The main difference between the regular and the organic Rankine cycle is the fluid used in each cycle. In the steam Rankine cycle, only water is used while there are hundreds of operating fluids that can be used for Organic Rankine cycle $e^{6,7}$.

\section{Application of cogeneration in a petrochemical plant}

A stable supply of energy and electricity is one of the most essential principles in the continuity of plant operation. An interruption in the power supply, causes a significant waste in the production and it is very important from safety aspects of industrial unit by appearing the possible risks ${ }^{8}$. So most of the petrochemical plants, require their own electrical supply as to be assured of system performance. In one of the petrochemical plants, an economical analysis of the cogeneration system in comparison with the existing situation (ordinary boilers for supplying steam of the process and purchasing electricity from the grid) were studied ${ }^{9}$. Power demand in this unit was approximately 50 $\mathrm{MW}$, and the whole steam needed in the process was $93 \mathrm{ton} / \mathrm{h}$. For the analysis of $\mathrm{CHP}$, and taking into account the future development, the power demand has increased to $65 \mathrm{MW}$ unit.

Steam turbines of $25 \mathrm{MW}$ are capable of producing power of $20.7 \mathrm{MW}$ at the site. Since the gas supplier cannot guarantee the supply of diluted gas, therefore hybrid status was considered for the gas turbine. A steam turbine generator with a capacity of $25 \mathrm{MW}$ was chosen to get the steam with $19 \mathrm{bar}$ and 25 bar pressure.

\section{Simultaneous production of water, power and refrigeration, with the use of the Organic Rankine cycle}

In the oil, gas and petrochemical industries, low pressure steam (usually output of the steam turbines forms the dominant part) discharges to the atmosphere and or condenses by the sea water or other cooling media and returns to the system. According to the thermodynamic principles, heat engines may be used between two high temperature and low temperature sources to transform a part of heat to the electric power. Power production of cold media and fresh water is an important advantage of this cycle. Choosing operating fluid and operation condition of cycle between hot and cold media is the most important parameters in design of the cycle. 
Analysis of power and cooling production cycle

Trans

butene is an operating fluid which is pumped to the shell \& tube heat exchanger $(\mathrm{HX})$. It is partially evaporated by the condensing low pressure steam (LPS). The evaporated part of operating fluid is separated in a flash drum and introduced to the expansion turbine to produce power (electricity). The liquid portion of trans- butene leavings flash drum joins to leaving portion of this fluid from expansion turbine. This stream is used as cooling or refrigeration media. The LPC ( low pressure condensate) stream leaving heat exchanger is used as a boiler feed water in steam generation process..

\section{Detailed analysis of the process}

According to the data of one of the old petrochemical plants, the amount of surplus LPS in plant is $10 \mathrm{Ton} / \mathrm{hr}$. Complete information on the LPS steam is given in the table (1). LPS steam has saturated conditions and transfers its latent heat of evaporation in the exchanger of $\mathrm{HX}$ cycle of power and cooling production into the operating fluid. A saturated liquid like, called LPC is coming out of it.

The process flow diagram of the cycle is presented in the fig 2

Table 1: LPS specification

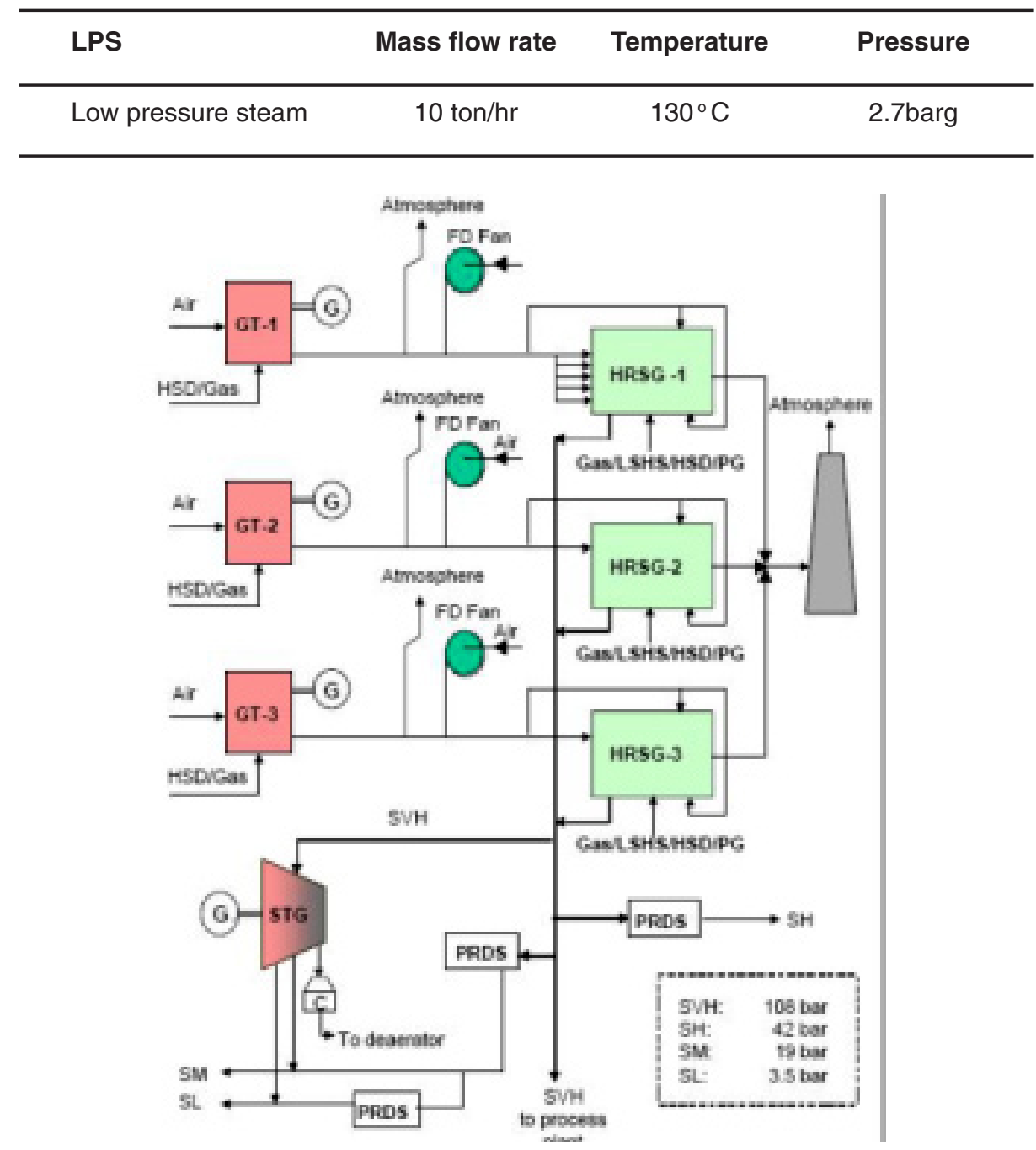

Fig. 1: Schematic of cogeneration in a petrochemical unit 


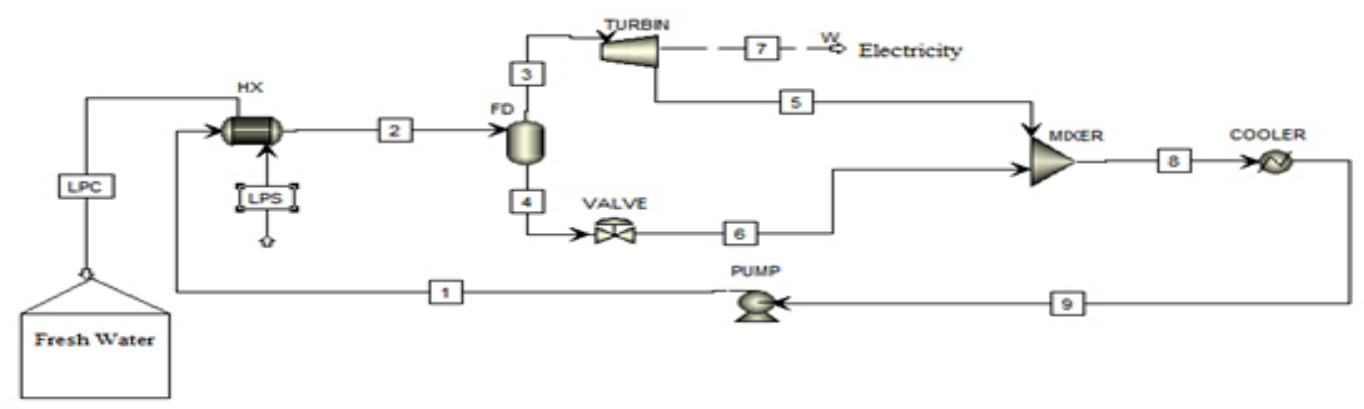

Fig. 2: Concurrent production cycle of fresh water, electricity and refrigeration

Table 2: Streams specifications

\begin{tabular}{lcccc}
\hline $\begin{array}{l}\text { Stream } \\
\text { No. }\end{array}$ & $\begin{array}{c}\text { Compounds (kg/hr) } \\
\text { (Water/trans-butene) }\end{array}$ & $\begin{array}{c}\text { Temperature } \\
(\mathbf{K})\end{array}$ & $\begin{array}{c}\text { Pressure } \\
(\mathbf{a t m})\end{array}$ & $\begin{array}{c}\text { Liquid fraction / } \\
\text { gas fraction }\end{array}$ \\
\hline 1 & $0 / 70000$ & 283 & 1 & $0 / 1$ \\
2 & $0 / 70000$ & 273 & 1 & $0.95 / 0.05$ \\
3 & $0 / 42152$ & 343 & 7.8 & Jan-00 \\
4 & $0 / 27847$ & 343 & 7.8 & $0 / 1$ \\
5 & $0 / 42152$ & 259 & 0.1 & Jan-00 \\
6 & $0 / 27847$ & 225 & 0.1 & $0.66 / 0.34$ \\
8 & $0 / 70000$ & 225 & 0.1 & $0.93 / 0.07$ \\
9 & $0 / 70000$ & 283 & 0.1 & $0 / 1$ \\
LPC & $10000 / 0$ & 320 & 2.66 & $0 / 1$ \\
LPS & $10000 / 0$ & 403 & 2.66 & Jan-00 \\
\hline
\end{tabular}

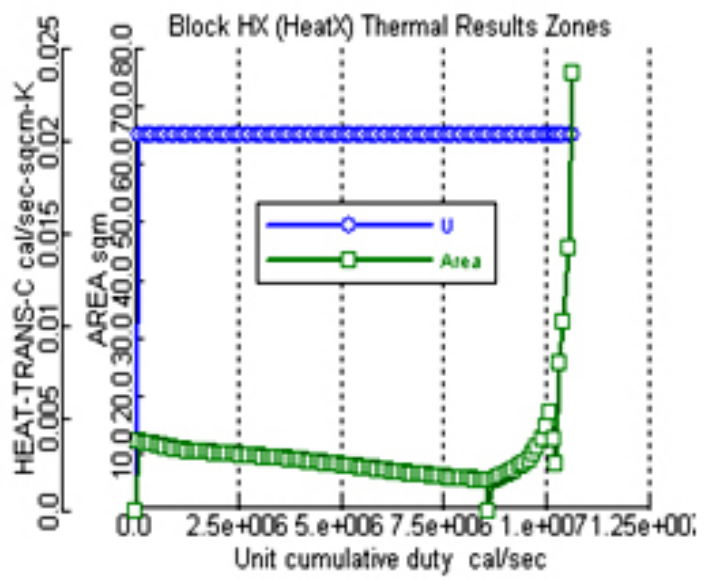

Fig. 3: Heat exchanger performance curve. Heat duty vs. Area and heat transfer coefficient

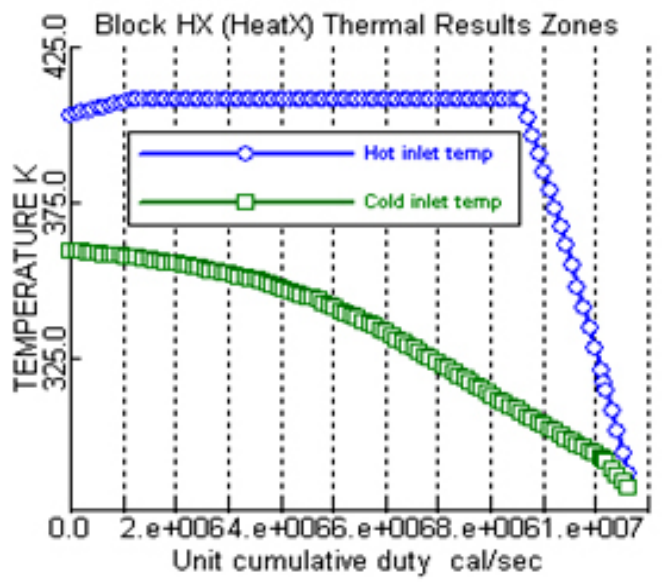

Fig. 4: Hot and cold stream temperature vs. Heat duty of heat exchanger 


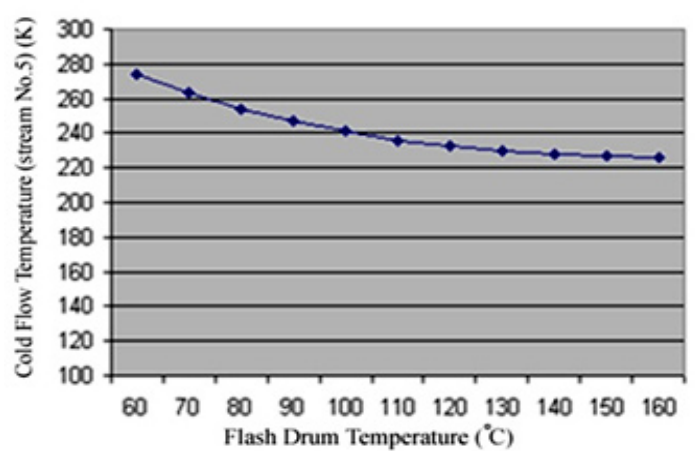

Fig. 5: Flash drum temperature vs. Temperature of the produced cold stream

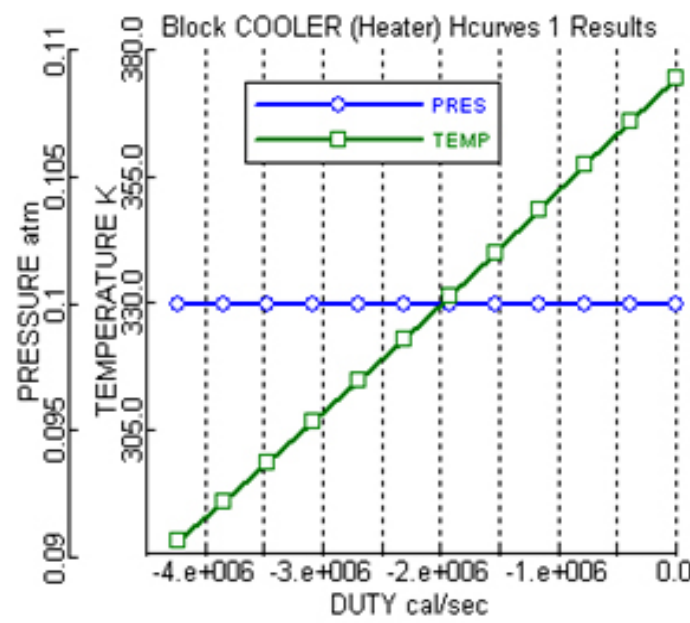

Fig. 7: Temperature and pressure of process fluid in air cooler vs. Heat duty

Table 3: Simulation results for ORC cycle

\begin{tabular}{lcc}
\hline & Stream & Production rate \\
\hline Fresh water & LPC & $10000(\mathrm{~kg} / \mathrm{hr})$ \\
Electricity & 7 & $1533(\mathrm{kw})$ \\
Refrigeration & 5 & $259.7(\mathrm{k})$ \\
& 8 & $225.7(\mathrm{k})$ \\
\hline
\end{tabular}

\section{Simulation results}

The simulation is done in hysys software and its result is presented in table (2).

Stream number 2 which is the cold outlet stream of the $\mathrm{HX}$ converter has liquid and vapor phases. The higher the percentage of steam phase

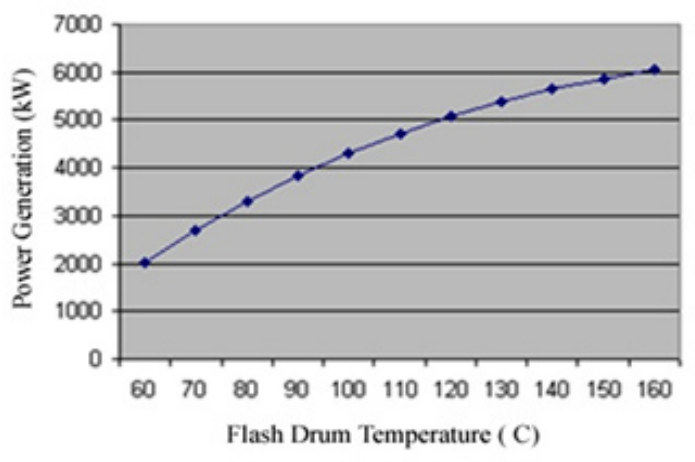

Fig. 6: Flash drum temperature vs. Power generation

\begin{tabular}{|c|c|c|c|}
\hline Summary & Performance Curve & \multicolumn{2}{|c|}{ Utifty Usage } \\
\hline \multicolumn{4}{|l|}{ Pump results - } \\
\hline Fluid power: & 2.08413191 & $\mathrm{~kW}$ & $\checkmark$ \\
\hline Brake power: & 3.05348682 & kw & $\checkmark$ \\
\hline Electricity: & 3.05348682 & kW & $\checkmark$ \\
\hline Volumetric flow rate: & 1371.25215 & $V / \min$ & $\checkmark$ \\
\hline Pressure change: & 0.9 & atm & $\checkmark$ \\
\hline NPSH available: & -7.1473892 & $\mathrm{~m} \cdot \mathrm{kg} / \mathrm{kg}$ & $\checkmark$ \\
\hline NPSH required: & & & $\checkmark$ \\
\hline Head developed: & 10.9297187 & $\mathrm{~m} \cdot \mathrm{kg} / \mathrm{kg}$ & $\checkmark$ \\
\hline Pump efficiency used & 0.68254164 & & \\
\hline Net work required. & 3.05348682 & kW & $v$ \\
\hline
\end{tabular}

Fig. 8: Simulation result for pump in hysys

in this flow, more steam will be extracted by flash drum (FD). So, the amount of mass flow of stream 3 will be more and as a result of that, more electricity generated by the turbine. Hence, temperature of the hot outlet stream of the converter or that of LPC flow get reduced upto $47^{\circ} \mathrm{C}$ until the maximum thermal exchange between the two, hot and cold streams, are reached and thus it creates the maximum steam phase in stream 2

The operational temperature of flash drum affects the temperature of cold utility produced during power generation. It also affects the amount of power generation. These effects are presented in graph 5 \& 6. According to tese graphs the higher the flash drum temperature can produce more electricity and lower cold utility temperature which means more benefit. 
Diagram (6), relating to the designed organic Rankine cycle cooler and signifies the total Duty amount on the basis of temperature and pressure.

Pump is also an important equipment of the cycle, and the simulation results for it are illustrated in fig (8).

The summarized results of ORC application for heat recovery from surplus LP steam in petrochemical plant is presented in table 3 .

\section{CONCLUSION}

In some refineries and petrochemical complexes, LP steam discharges into the atmosphere and or condensed by the sea water and returns to the system. In this article, the method of re-use of excess low pressure steam energy and mass was studied as to get the sweet and fresh water, power and refrigeration with the help of organic Rankine cycle and an organic operating fluid of trans-butene, and with the optimal cyclic design, tried to provide a guideline for the use of these valuable energy. Concurrent production of sweet and fresh water, production of a significant amount of electricity and refrigeration with industrial and non-industrial purposes are the characteristics of this system ${ }^{10}$. Note that, the aforesaid cycle has not used any type of fossil energy sources, except the wasted energies. Therefore, its fuel consumption is zero and from the point of environmental issues, the system is absolutely clean and green. On the other hand, the produced distilled water in this system and the condensed LP steam will be used as compensatory water in the boilers or in other places. These types of cycles are low pressure system with no trouble and by the time of exploitation and operation they need no additional crews for control of the system. At the time of launch, setup and exploitation, people in the complex, are given the training easily and will be able to do the work up by themselves alone meaning the setting up, exploitation, repairing and maintenance of the system.

\section{ACKNOWLEDGEMENT}

The above investigation was supported through grant by the Islamic Azad University Islamshahr Branch and is gratefully acknowledged.

\section{REFERENCES}

1. Wells, J.; Proceedings of the $25^{\text {th }}$ world energy engineering congress. 2003, 63-71

2. Deng, J.; Wang, R.Z.; Han, G.Y. Progress in Energy and Combustion Science. 2011, 37, 172-203

3. Krewitt, W.; Klebmann, C.; Capone, C. ; Stricker, E.; Graus, W.; Hoogwijk, M.; Supersberger, N.; Winterfeld, U. von; Samadi, S. Report-no.(UBA-FB)001323/E German Federal Environment Agency, 2009.

4. MacLeay, I.; Harris, K.; Annut, A. Digest of United Kingdom Energy Statistics,. A National Statistics Publication London, 2009, ISBN9780115155246
5. Ge,Y.T.; Tassou, S.A.; Chaer, I.; Suguartha, N. Appl. Energy. 2009 , 86, 2317-2326

6. Khaliq, A.; Kumar, R.; Dincer, I. Int. J. Energy. Res. 2009, 33, 737-744

7. Onovwiona, H.I.; Ugursal, V.I. Renew. Sustain. Energy. Rev. 2006, 10, 389-431

8. Lai Sau Man, Hui Chi Wai. Appl. Energy. 2010, 87, 2868-2880

9. Meng, X.; Yang, F.; Bao, Z.; Deng, J.; Serge, N. N.; Zhang, Z. Appl. Energy. 2010,87, 2050-2061

10. Fumo, N.; Mago, P. J.; Chamra, L. M. Appl. Energy. 2009, 86, 928-932. 